\title{
High-temperature electrical conductivity of aluminium nitride
}

\author{
V. L. RICHARDS \\ Allied Automotive, Troy, Michigan, USA \\ T. Y. TIEN, R. D. PEHLKE \\ University of Michigan, Ann Arbor, Michigan, USA
}

\begin{abstract}
The electrical conductivity of hot-pressed polycrystalline aluminium nitride doped with oxygen and beryllium was measured as a function of temperature from 800 to $1200^{\circ} \mathrm{C}$ and over a range of nitrogen partial pressure from $10^{2}$ to $10^{5} \mathrm{~Pa}$. The effect of beryllium dopant, the independence of conductivity from nitrogen partial pressure, and the observed activation energy suggested extrinsic electronic species or aluminium vacancies as charge carriers. Polarization measurements made with one electrode blocking to ionic species indicated that the aluminium nitride with oxygen impurity was an extrinsic electronic conductor.
\end{abstract}

\section{Introduction}

Aluminium nitride has both existing and possible applications in moderate and in high temperature environments. At moderate temperatures, aluminium nitride is used in surface acoustic wave delay line devices because of its piezoelectric properties and high acoustic velocity [1]. Because of the high thermal conductivity reported by Slack [2] and the low electrical conductivity at moderate temperature, aluminium nitride is considered potentially an excellent electronic substrate material. Also, thin layers have been used as diffusion masks and dielectric layers [3]. Successful high-temperature experiments with aluminium nitride as a chemical potential sensor have been reported by Fischer and Schuh [4] and Fischer et al. [5]. However, others have attempted this application $[6,7]$ but concluded that aluminium nitride conducts primarily by electronic species at high temperature and is, therefore, unsuitable.

The aluminium nitride studied in this investigation was in two chemical conditions - oxygen-containing and beryllium-and-oxygen-containing. The hot-pressed, polycrystalline nitride was at oxygen saturation with respect to the $\mathrm{Al}_{(8 / 3+x / 3)} \mathrm{O}_{(4-x)} \mathrm{N}_{x}$ spinel in both cases [8]. The solubility of beryllium nitride in aluminium nitride has been measured by Schneider et al. [9]. The beryllium-containing material was investigated to observe the effect of an aliovalent cation in solution. The effect of the beryllium should yield information about defect structure and dominant carrier species.

Electrical conductivity was measured by the fourpole d.c. method [10] as a function of nitrogen partial pressure and temperature for both sample conditions. As the conductivity was independent of nitrogen partial pressure and previous investigators had made attempts at e.m.f. measurements [4-7], a polarization experiment was devised to test for ionic conduction.

\section{Experimental method}

\subsection{Sample preparation}

The aluminium nitride material employed in this investigation contained oxygen as an impurity. A survey of commercially available aluminium nitride powders indicated that even the purest contain more than $0.1 \%$ oxygen. Also, two separate investigations have reported that aluminium nitride powders without some oxygen impurity will not densify even under high pressure [11, 12]. Slack and McNelly [13] reported some success in growing single crystals of aluminium nitride as large as $2 \mathrm{~cm}$ long. These single crystals had oxygen contents as low as 500 p.p.m. The aluminium nitride which was the subject of this investigation was saturated with oxygen with respect to the $\mathrm{Al}_{(8 / 3+x / 3)} \mathrm{O}_{(4-x)} \mathrm{N}_{x}$ spinel. Using the correlation of Lejus [14] the value of $x$ for the spinel phase is estimated to be 0.50 from the lattice parameter. For comparison, it is noted that McCauley and Corbin [8] found $x=0.77$ at AlN saturation in the temperature range 1750 to $1850^{\circ} \mathrm{C}$.

The samples were hot-pressed in a graphite resistance furnace using a boron-nitride-coated graphite die at $1850^{\circ} \mathrm{C}$, under $19.6 \mathrm{MPa}$ pressure for $3 \mathrm{~h}$ as detailed by Richards [15].

\subsection{Conductivity measurements}

The four-pole specimen hot-pressed from CERAC powder (CERAC Inc., Milwaukee, Wisconsin) was heat-treated for $24 \mathrm{~h}$ at $50^{\circ} \mathrm{C}$ above the maximum test temperature while buried in aluminium nitride powder in a carbon resistance furnace. The berylliumcontaining specimen was heat-treated while buried under aluminium nitride powder in a flowing nitrogen$1 \%$ hydrogen atmosphere for $48 \mathrm{~h}$ at $1573 \mathrm{~K}$. However, this sample required four weeks additional holding time at temperature in the sample holder under a nitrogen-hydrogen atmosphere to obtain reproducible results. The samples were characterized by $\mathrm{X}$-ray 


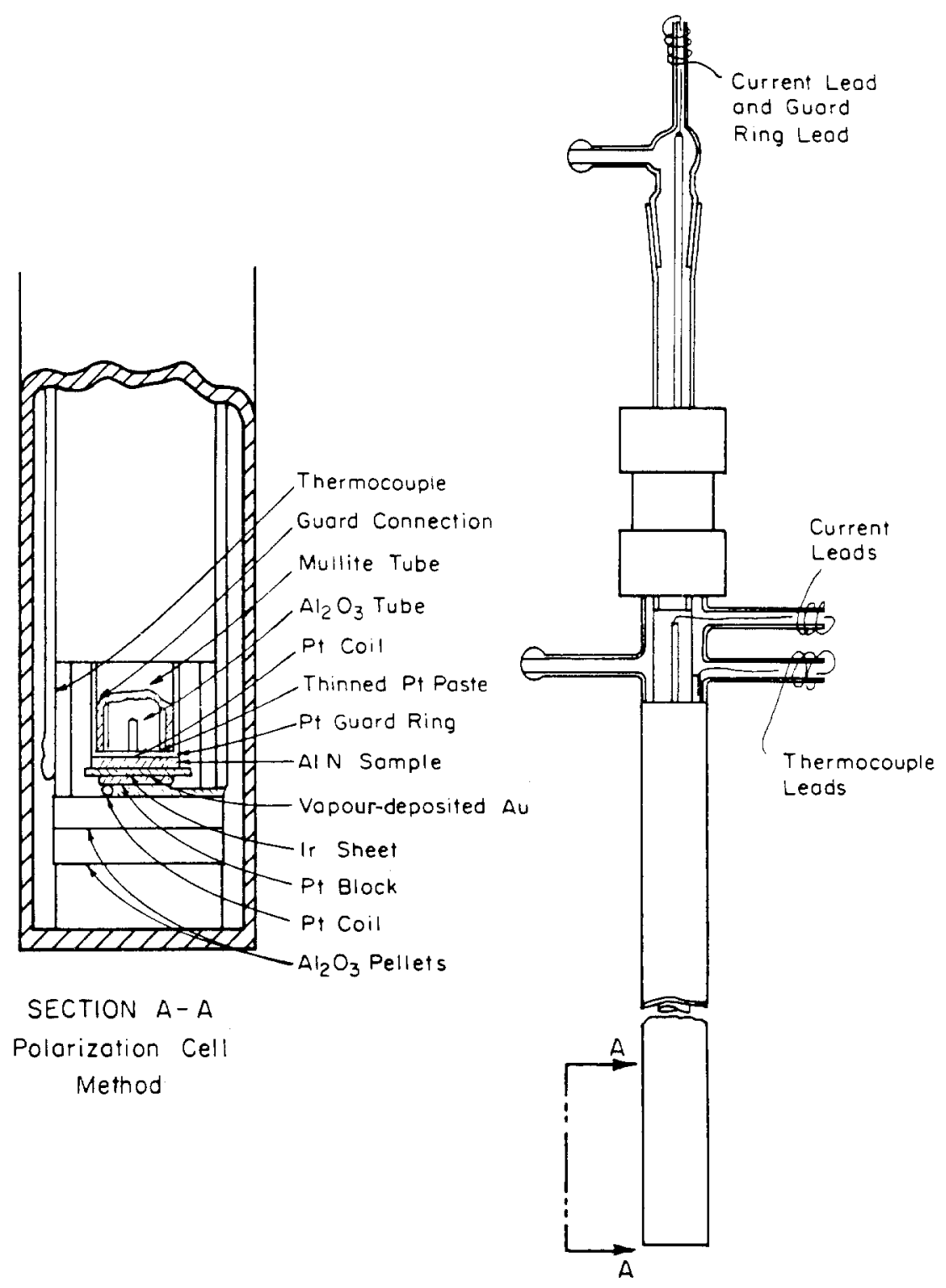

Figure I Electrodes and sample holder for polarization measurement.

diffraction before and after the conductivity measurements. Bulk density was measured by an Archimedes method using suspended weights of lacquer-coated specimens in air and water. Four-probe conductivity measurements were performed as described by Blumenthal and Seitz [10] and Rapp and Shores [16] using samples of rectangular cross-section. The current was applied from a current source, monitored with a Keithly model 191 digital multimeter with a 1901 current shunt. Voltage across the gauge section was measured with a Keithley model $610 \mathrm{C}$ electrometer. The leads and reaction tube were shielded.

A controlled atmosphere was provided with nitrogen-hydrogen-argon mixtures. Nitrogen partial pressures of $1.01 \times 10^{2}$ to $1.01 \times 10^{5} \mathrm{~Pa}$ were used in mixes containing $1 \%$ hydrogen. A temperature range of 800 to $1200^{\circ} \mathrm{C}$ was investigated. Temperature increases were made stepwise followed by periods of equilibration until results were reproducible. Temperature decreases were made in small increments, varying rates of decrease from 8 to $70^{\circ} \mathrm{Ch}^{-1}$ to observe any effects of "frozen-in" defect structure.

\subsection{Polarization measurements}

Polarization measurements were made on a sample from the same pressing as the aluminium nitride sample with oxygen impurity on which conductivity measurements were made. The method of Patterson et al. [17], was applied except that a guard ring was used around the reversible electrode and the reversible electrode involved a gas phase and an electronic conductor instead of a two-phase solid. The apparatus was verified using a calcia-stabilized zirconia sample and an oxygen-containing gas. The electrodes and the sample holder for this polarization experiment are shown in Fig. 1. In the oxide cell the reversible electrode was the anode, in the aluminium nitride cell, the reversible electrode was the cathode.

\section{Experimental details}

The samples were hot pressed from powders for which transition metal analyses were specified by the supplier (CERAC Inc.) as less than $0.05 \%$ iron and $0.005 \%$ copper. Chemical analysis for carbon and oxygen were performed by Leco Corporation, St Joseph, Michigan, by combustion methods. The results of these analyses are shown in Table $I$.

TABLE I Chemical analyses of aluminium nitride samples

\begin{tabular}{lll}
\hline Sample & Carbon (wt \%) & Oxygen (wt \%) \\
\hline $4 \mathrm{PO} 1$ & 0.057 & 2.47 \\
$4 \mathrm{PO} 4$ (BeO-doped) & 1.47 & 1.72 \\
\hline
\end{tabular}




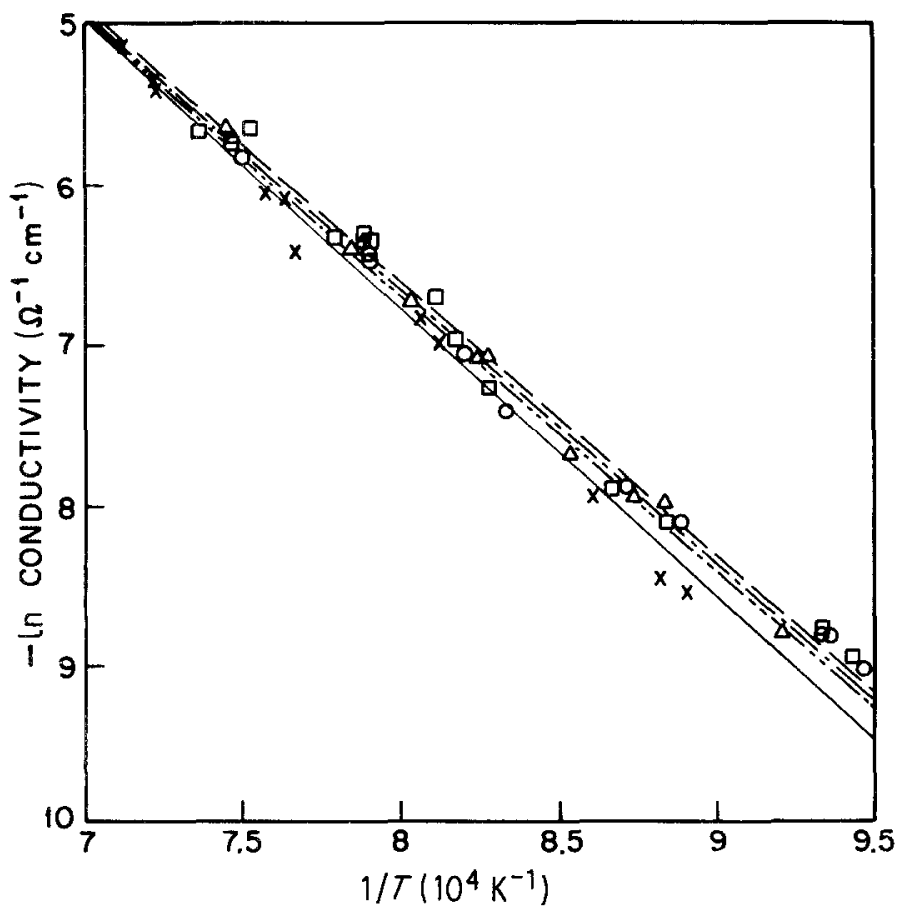

Figure 2 Four-pole conductivity results for aluminium nitride sample $4 \mathrm{POl}$ at various nitrogen partial pressures. For clarity, the points shown are the average of nine datum points at the same temperature and nitrogen partial pressures. However, the regression correlations were run on the full data set including all points to give the lines shown in the figure. $P_{\mathrm{N}_{2}}=(\times, \longrightarrow) 1.014 \times 10^{2} \mathrm{~Pa},(\mathrm{O},--)$ $1.014 \times 10^{3} \mathrm{~Pa}, \quad(\triangle-\cdot-) \quad 1.014 \times 10^{4} \mathrm{~Pa}, \quad(\square,---)$ $1.014 \times 10^{5} \mathrm{~Pa}$

$\mathrm{X}$-ray diffraction results indicated that the aluminium-oxygen-nitrogen spinel was present as a minor second phase both before and after conductivity measurement. The beryllium-doped specimen had both the spinel and either $\mathrm{Be}_{3} \mathrm{~N}_{2}$ or $\mathrm{BeO}$ as second phases. Schneider et al. [9] showed that up to $1.5 \mathrm{~mol}^{\%} \mathrm{Be}_{3} \mathrm{~N}_{2}$ is soluble in AIN with lattice parameter, $a$, decreasing to $0.310 \mathrm{~nm}$ from $0.312 \mathrm{~nm}$ for pure AlN; similarly, the measured lattice parameter, $a$, for the berylliumdoped wurtzite structure AlN in this study was $0.309 \mathrm{~nm}$ compared to $0.314 \mathrm{~nm}$ for AIN with only oxygen impurity. This indicates $\mathrm{Be}_{3} \mathrm{~N}_{2}$ in solid solution in the AIN as found by Schneider et al. It is also notable that the aluminium nitride powder diffraction pattern conformed to the wurtzite structure [18] and the polytypes reported by McCauley and Corbin [8] were not observed. Another feature of the X-ray diffraction results was that despite the large duration at temperature for testing, the eutectoid decomposition of the spinel reported by Lejus [14] was not observed. The aluminium nitride for the polarization sample was from the same pressing as sample 4PO1. The cubic zirconia electrolyte used to verify the polarization apparatus was $7.5 \mathrm{wt} \%$ calcia impervious cubic zirconia from Corning Glass Works, Ohio.

\section{Experimental results}

\subsection{Conductivity results}

The conductivity results are shown in the plots of $\log$ conductivity against inverse temperature (Figs 2 and 3). Fig. 2 represents the aluminium nitride with oxygen impurity, Fig. 3 shows the effect of the beryl- lium addition. The lines were fit using least squares regression correlation. The results in terms of constants, coefficients and activation energies are summarized in Table II. The lines which were fitted are plotted along with the conductivity results of other investigators $[6,7,19]$ in Fig. 4.

The results for aluminium nitride with oxygen impurity agree well with those of Frances and Worrell [6] and Fischer and Schuh [19] and show little or no dependence on nitrogen partial pressure between $10^{2}$ and $10^{5} \mathrm{~Pa}$. This independence makes it reasonable to presume one mechanism for conduction over the partial pressure range studied, so that an activation energy of $1.42 \times 10^{5} \pm 1 \times 10^{3} \mathrm{~J} \mathrm{~mol}^{-1}$ can be determined from a linear regression correlation on all of the data from sample 4PO1.

\subsection{Polarization results}

The results of the polarization measurements take two forms:

1. The steady state voltage and current density which are fitted to mathematical expressions for current density with a blocking electrode (cf. Richards [15] and Patterson et al. [17]).

2. The voltage-time behaviour at constant current for zero initial current.

Typical voltage-time behaviour for the cell:

$$
\mathrm{Pt} / \mathrm{O}_{2}, \mathrm{Ar}\left\|(\mathrm{CaO}) \mathrm{ZrO}_{2}\right\| \mathrm{Au}, \mathrm{Pt}
$$

is shown in Fig. 5. In that figure, we see the approach to steady state behaviour which is typical of an ionic conductor with an electrode blocking ionic species.

TA BLE II Linear regression correlation results of four-pole conductivity of sample 4POI

\begin{tabular}{llll}
\hline $\begin{array}{l}\text { Nitrogen partial } \\
\text { pressure }(\mathrm{Pa})\end{array}$ & Constant & $\begin{array}{l}\text { Coefficient } \\
\text { of } 1 / T\left(10^{-4} \mathrm{~K}^{-1}\right)\end{array}$ & $\begin{array}{l}\text { Activation energy } \\
\left.(\mathrm{J} \mathrm{mol})^{-1}\right)\end{array}$ \\
\hline $10^{2}$ & $7.79 \pm 0.194$ & $-1.822 \pm 0.0242$ & $1.512 \times 10^{5} \pm 1.9 \times 10^{3}$ \\
$10^{3}$ & $6.56 \pm 0.067$ & $-1.653 \pm 0.0079$ & $1.367 \times 10^{5} \pm 0.95 \times 10^{3}$ \\
$10^{4}$ & $6.87 \pm 0.075$ & $-1.687 \pm 0.0091$ & $1.397 \times 10^{5} \pm 0.96 \times 10^{3}$ \\
$10^{5}$ & $6.84 \pm 0.116$ & $-1.684 \pm 0.0142$ & $1.397 \times 10^{5} \pm 0.96 \times 10^{3}$ \\
\hline
\end{tabular}




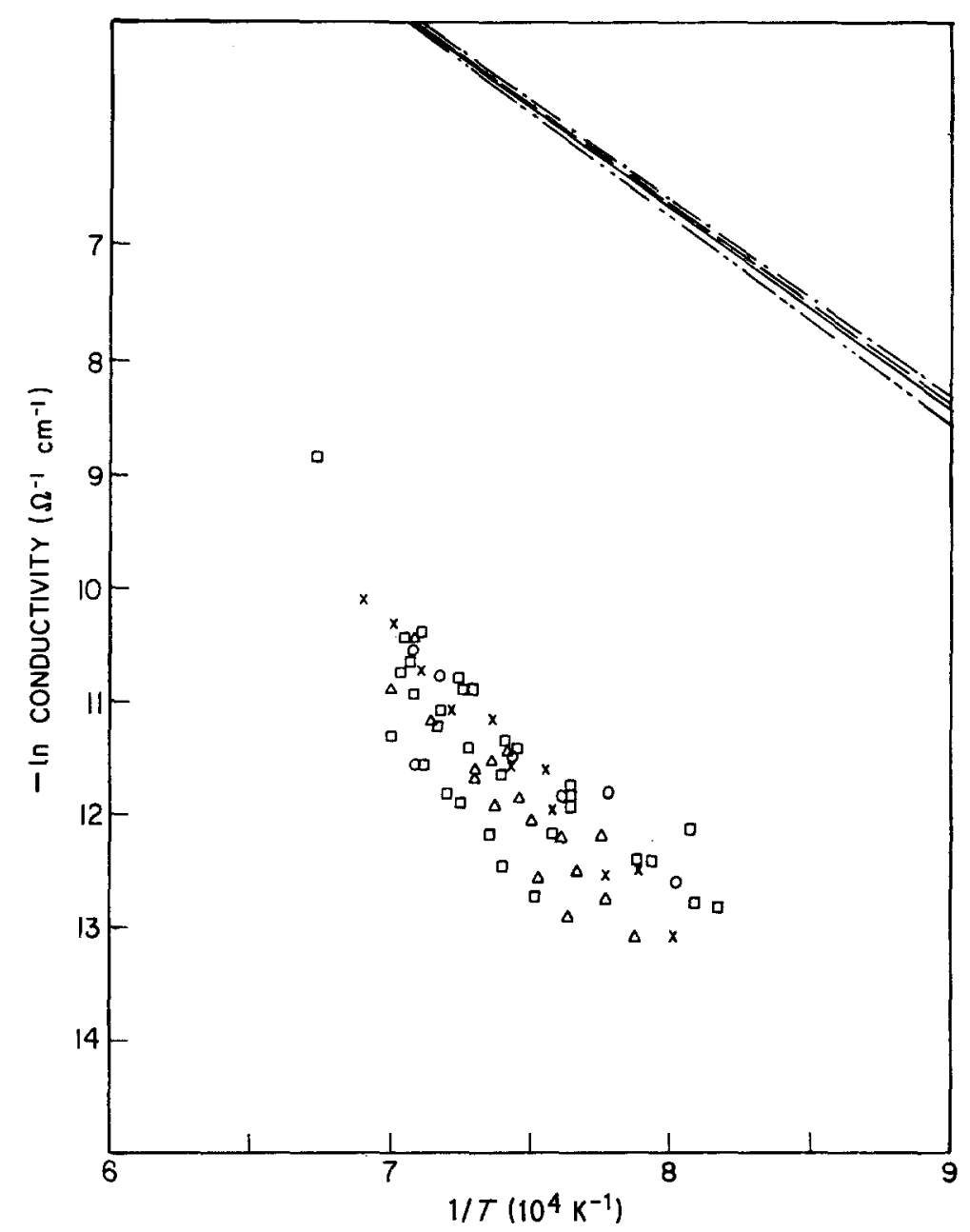

Figure 3 Four-pole conductivity results of BeOdoped sample (4PO4) compared to sample 4PO1. Correlation lines from $4 \mathrm{PO} 1$ are shown for comparison. Each point shown is the average of nine points for the same temperature and nitrogen pressure for clarity. $P_{\mathrm{N}_{2}}=(\mathrm{x},--) 1.014 \times 10^{4} \mathrm{~Pa}$, $(\mathrm{O},--) 1.014 \times 10^{3} \mathrm{~Pa},(\Delta, \cdots) 1.014 \times 10^{2} \mathrm{~Pa}$, $(\square, \square) 1.014 \times 10^{5} \mathrm{~Pa}$.

The cell using the aluminium nitride with oxygen impurity as the electrolyte:

$$
\mathrm{Pt} / \mathrm{N}_{2}, \mathrm{Ar}\|\mathrm{AlN}(\mathrm{O})\| \mathrm{Au}, \mathrm{Pt}
$$

did not show the initial voltage rise at constant current typical of the ionic conductor with one blocking electrode, as indicated in Fig. 5. The steady state voltage

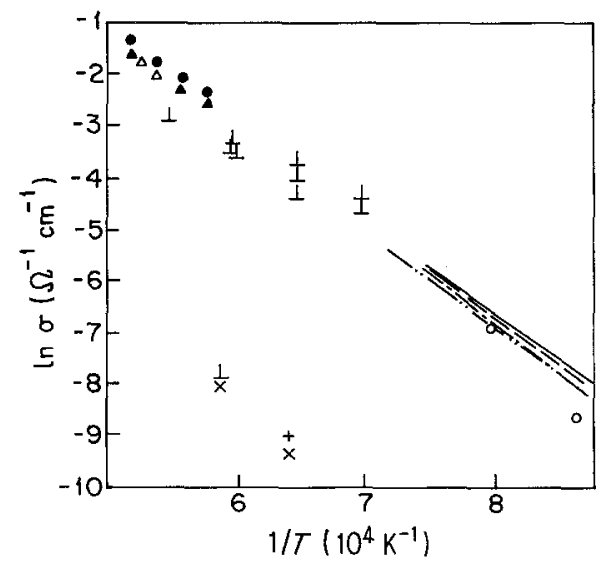

Figure 4 Summary of conductivity results from aluminium nitride sample 4PO1 and comparison with literature results. $(-. \cdot-) 4 \mathrm{PO} 1$ at $P_{\mathrm{N}_{2}}=1.014 \times 10^{2} \mathrm{~Pa},(-\cdot) 1.014 \times 10^{3} \mathrm{~Pa},(--) 1.14 \times 10^{4} \mathrm{~Pa}$, $\stackrel{(}{\longrightarrow} 1.014 \times 10^{5} \mathrm{~Pa},(\bullet)$ Fischer and Schuh two-pole result at $P_{\mathrm{N}_{2}}=10.14 \mathrm{~Pa}$ [19]; Fischer and Schuh four-pole result at $P_{\mathrm{N}_{2}}=(\Delta) 1.014 \mathrm{~Pa}$ [19], (ム) $1.014 \times 10^{5} \mathrm{~Pa}[19] ;(\perp)$ Fischer and Schuh two-pole result at $P_{\mathrm{N}_{2}}=1.014 \times 10^{5} \mathrm{~Pa}$ [19]; (O) Frances and Worrell two-pole result at $1.014 \times 10^{5} \mathrm{~Pa} \geqslant P_{\mathrm{N}_{2}} \geqslant 10.14 \mathrm{~Pa}$ [6]; (+) Gorbatov and Kamyshov two-pole result at $P_{\mathrm{N}_{2}}=19.3 \mathrm{~Pa}$ [7]; (x) Gorbatov and Kamshov two-pole result at $P_{\mathrm{N}_{2}}=1.014 \times$ $10^{5} \mathrm{~Pa}[7]$. and current density data were fit to a mathematical expression similar to that of Patterson et al., specifically

$$
I_{\mathrm{f}} /[1-\exp (u)]=R T / F L\left(\sigma_{\mathrm{e}^{\prime}}^{0}+\sigma_{\mathrm{h}}^{0} \cdot \exp [-u]\right)
$$

where $u=E F / R T$ where $e$ is applied voltage, $F$ is Faraday's constant, $R$ is the gas constant and $T$ is absolute temperature. $I_{\mathrm{f}}$ is current density and $L$ is sample thickness. A linear curve fit yields values of $\sigma_{\mathrm{e}^{\prime}}^{0}$ and $\sigma_{\mathrm{h}}^{0}$, partial conductivities of electrons and holes, respectively, for one set of conditions of temperature and nitrogen partial pressure. The resulting partial conductivities for electrons and holes are shown in Fig. 6, along with the total conductivities measured by the 4-pole procedure described above. It should be noted that there was some scatter in the high temperature measurements because of temperature control difficulties.

\section{Discussion}

\subsection{Conductivity results}

The conductivity which was measured is not likely to be intrinsic because the activation energy is much lower than would be calculated from the $419 \mathrm{~kJ} \mathrm{~mol}^{-1}$ "band gap" for pure AIN [20] or the $460 \mathrm{~kJ} \mathrm{~mol}^{-1}$ estimate of Schottky defect formation enthalpies from the Barr-Lidiard correlation [25].

Because the conductivity did not depend on nitrogen partial pressure, the presence of the oxygen impurity suggested that the carrier species could be extrinsic aluminium vacancies or electronic species. 


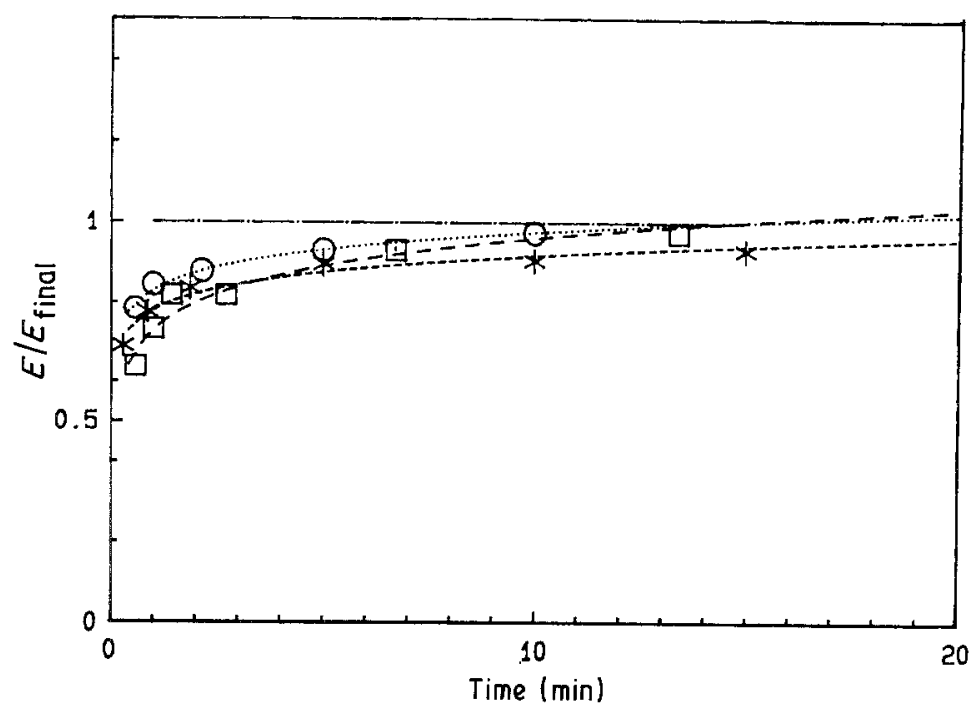

Figure 5 Composite of voltage-time transients for $\mathrm{ZrO}_{2}(\mathrm{CaO})$ at $1310 \mathrm{~K}, 3.1 \times 10^{2} \mathrm{~Pa}:(\square,---)$ current $=46.6 \mu \mathrm{A} ;(\mathrm{O}, \cdots)$ current $=53.8 \mu \mathrm{A} ;(*,---)$ current $=31.2 \mu \mathrm{A} ;(-\cdot-)$ aluminium nitride, typical result.

Fischer and Schuh [21] found that the sign of the thermoelectric effect indicated a negative relative charge of the carrier species in aluminium nitride with oxygen as the primary impurity. Either vacancies or electronic species can be formed by the solution of the $\mathrm{Al}_{(8 / 3+x / 3)} \mathrm{O}_{(4-x)} \mathrm{N}_{x}$ spinel into the aluminium nitride as follows

$$
\begin{gathered}
\mathrm{Al}_{(8 / 3+x / 3)} \mathrm{O}_{(4-x)} \mathrm{N}_{x} \stackrel{\mathrm{AlN}}{\longrightarrow}(4-x) \mathrm{O}_{\mathrm{N}}^{\prime}+x \mathrm{~N}_{\mathrm{N}} \\
+(8 / 3+x / 3) \mathrm{Al}_{\mathrm{A} 1}+(4 / x-x / 3) V_{\mathrm{Al}}^{\prime \prime \prime}
\end{gathered}
$$

for aluminium vacancies, or

$$
\begin{gathered}
\mathrm{Al}_{(8 / 3+x / 3)} \mathrm{O}_{(4-x)} \mathrm{N}_{x} \stackrel{\text { AlN }}{\longrightarrow}(8 / 3-4 x / 3) \mathrm{O}_{\mathrm{N}} \\
+(8 / 3-x / 3) \mathrm{Al}_{\mathrm{Al}}+x \mathrm{~N}_{\mathrm{N}}+(4 / 6+x / 6) \mathrm{O}_{2(\mathrm{~g})}
\end{gathered}
$$

with a donor reaction, to produce electrons

$$
\mathrm{O}_{\mathrm{N}} \rightarrow \mathrm{O}_{\mathrm{N}}^{\cdot}+e^{\prime}
$$

In either of the above cases, examination of the elec-

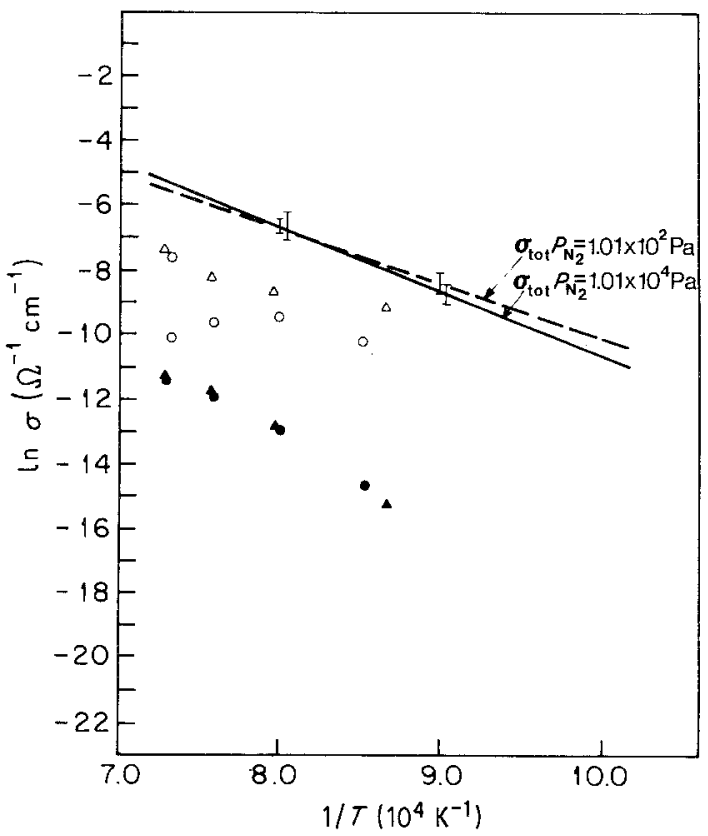

Figure 6 Partial electronic conductivities of aluminium nitride with oxygen impurity compared to total conductivity as measured by the four-pole method (sample 4PO1). (O) $\sigma_{\mathrm{e}}, P_{\mathrm{N}_{2}}=1.01 \times 10^{2} \mathrm{~Pa} ;(\Delta)$ $\sigma_{e}, P_{\mathrm{N}_{2}}=1.01 \times 10^{4} \mathrm{~Pa} ;(\bullet) \sigma_{\mathrm{h}}, P_{\mathrm{N}_{2}}=1.01 \times 10^{2} \mathrm{~Pa} ;(\Delta) \sigma_{\mathrm{h}}$, $P_{\mathrm{N}_{2}}=1.01 \times 10^{4} \mathrm{~Pa}$ troneutrality condition can give a reasonable interpretation of the decrease in conductivity with the addition of beryllium. Consider the electroneutrality condition for extrinsic aluminium vacancies as the predominant charge carrier:

$$
3\left[V_{\mathrm{Al}}^{\prime \prime \prime}\right]+\left[F_{\mathrm{Al}}^{\prime}\right]=\left[\mathrm{O}_{\mathrm{N}}^{\prime}\right]
$$

where $\left[V_{\mathrm{Al}}^{\prime \prime \prime}\right]$ is the concentration of aluminium vacancies, $\left[F_{\mathrm{A} I}^{\prime}\right]$ is the concentration of divalent cations on aluminium sites and $\left[\mathrm{O}_{\mathrm{N}}^{*}\right.$ is the concentration of divalent oxygens on nitrogen sites.

From this equation it is seen that increasing the concentration of divalent foreign cations by adding beryllium would decrease the concentration of aluminium vacancies and therefore the conductivity. A similar observation can be stated for the concentration of extrinsic electronic species if the oxygen on nitrogen sites was compensated by divalent cations on aluminium sites, specifically:

$$
\left[e^{\prime}\right]+\left[F_{\mathrm{Al}}^{\prime}\right]=\left[\mathrm{O}_{\mathrm{N}}\right]
$$

Activation energies and literature data can be used to argue for both extrinsic ionic and electronic species. The activation energy for conduction calculated from the temperature dependence of conductivity in this study is $154 \mathrm{~kJ} \mathrm{~mol}^{-1}$. This is reasonable as an activation energy for diffusion of extrinsic aluminium vacancies when compared to larger foreign cation species, such as those reported by Lamparter et al. [22]: $280 \mathrm{~kJ} \mathrm{~mol}^{-1}$ for vanadium, $271 \mathrm{~kJ} \mathrm{~mol}^{-1}$ for titanium and $377 \mathrm{~kJ} \mathrm{~mol}^{-1}$ for niobium. For the electronic species viewpoint, a "gap energy" was measured for aluminium nitride with oxygen impurity of $387 \mathrm{~kJ} \mathrm{~mol}^{-1}$ using optical methods [20, 23]. If this energy is considered as $\left(E_{\mathrm{g}}-E_{\mathrm{d}}\right)$, half of it is not too much greater than the observed activation energy of conduction.

Aluminium vacancies as the charge carrier would agree with one interpretation of measurements made by Fischer et al. [5] in which a cell including oxidecoated aluminium nitride gave e.m.f.s corresponding to aluminium potential. However, as indicated above, others [6], who took some precaution against developing a substantial surface oxidation layer, found no e.m.f.s and concluded that conduction was electronic. 
In order to resolve this difference, the polarization measurement was designed assuming aluminium vacancies as the dominant ionic carrier.

\subsection{Polarization results}

In polarization measurements on an ionic conductor with one blocking electrode, the resistivity is initially observed to increase with time, finally reaching a steady state, as with the calcia-stabilized zirconia in this study [24]. The rise time should be longer for aluminium nitride considering its lower conductivity and should be readily observable on the time scale of these measurements. This initial rise in resistance with time was not observed in the measurements on aluminium nitride. The partial electronic conductivities were determined by fitting the steady state values of voltage and current density to the model for cation vacancy defect species. The values thus determined are within an order of magnitude of the total conductivity measured by the four-probe technique. The difference between partial electronic conductivity as measured by the polarization method and the total conductivity as measured by the four-probe method may be due to contact resistances being present in the polarization measurement which were eliminated by the fourprobe method.

Therefore, aluminium nitride with oxygen impurity seems to be either an electronic conductor or a mixed conductor with an electronic transference number greater than one-tenth. Lack of time dependence of the resistivity during polarization argues for dominant electronic conduction. A donor reaction like that shown in Equation 3 is suggested, where either the oxygen impurity or a compensating defect is the donor.

\section{Conclusions}

The conductivity of oxygen-containing polycrystalline aluminium nitride was observed to be independent of nitrogen partial pressure from $10^{5}$ to $10^{2} \mathrm{~Pa}$ in the temperature range from 800 to $1200^{\circ} \mathrm{C}$. Beryllium was found to substantially decrease conductivity.

Applying defect chemistry to the analysis and examining the activation energies involved, it was concluded that the carriers were extrinsic electrons or aluminium vacancies. Polarization measurements showed that the predominant carriers were electronic species. A donor reaction involving the oxygen impurity or a compensating defect is suggested as the mechanism of charge carrier generation.

\section{References}

1. Courtland O. Dugger, "The Single Crystal Synthesis and Some Properties of Aluminum Nitride", AF CRL-
TR-75-0486, Air Force Cambridge Research Laboratories (August 1975).

2. G. A. SLACK, "Aluminum Nitride Crystal Growth", Final Report on Contract F 49620-78-C-0021, Directorate of Electronic and Solid State Sciences, Bolling AFB, DC (December 1979).

3. I. L. CHU, D. W. ING and A. J. NOREIKA, Solid State Electron. 10 (1968) 1023.

4. W. A. FISCHER and BERNARD SCHUH, Arch. Eisenhutenw. 46 (1975) 101.

5. W. A. FISCHER, H. DOREN and DIETER JANKE, ibid. 52 (3) (1981) 91.

6. R. W. FRANCIS and W. L. WORRELL, J. Electrochem. Soc. 123 (1976) 430

7. A. G. GORBATOV and V. M. Kamyshov, Sov. Powder Metall. 11 (1970) 917.

8. JAMES W. McCAUlEY and N. D. CORBIN, J. Amer. Ceram. Soc. 62 (1979) 476.

9. G. SCHNEIDER, L. J. GAUKLER and G. PETZOW, ibid. 63 (1980) 32.

10. R. N. BLUMENTHAL and M. A. SEITZ, "Experimental Techniques", Electrical Conductivity of Ceramics and Glass", Part A, edited by N. M. Tallan, (Marcel Dekker, New York, 1974) pp. 35-178.

11. S. PROCHAZKA and C. F. BOBIK, Mater. Sci. Res. 13 (1980) 321.

12. T. SAKAI and M. IWATA, J. Mater. Sci. 12 (1977) 1659.

13. G. A. SLACK and T. F. McNELLY, J. Crystal Growth 42 (1977) 560.

14. ANNe-Marie lejus, Rev. des Haute Temp. Refract. I (1964) 53.

15. V. L. RICHARDS, PhD thesis, University of Michigan (1982).

16. R. A. RAPP and D. A. SHORES, Electrochemical Measurements: Solid Electrolyte Galvanic Cells, in "Techniques of Metals Research", Vol. 4, edited by R. A. Rapp (Wiley, New York, 1970) 123.

17. JOHN W. PATTERSON, E. C. BOGREN and R. A. RAPP, J. Electrochem. Soc. 114 (1967) 752.

18. Joint Committee on Powder Diffraction Standards (J.C.P.D.S.), Swarthmore, Pennsylvania.

19. WILHELM ANTON FISCHER and BERND SCHUH, Arch. Eisenhutenw. 45 (1974) 745.

20. J. PASTRNAK, H. G. GRUMMEIS and C. OVREN, Phys. Status Solidi 32 (1975) 571.

21. WILHELM ANTON FISCHER and BERND SCHUH, Arch. Eisenhuttenw. 45 (1974) 839.

22. P. LAMPARTER, S. STEEB and A. GUKELBERGER, High Temp. High Press. 3 (1971) 727.

23. J. PASTRNAK and L. ROSKOVCOVA, Phys. Status Solidi 26 (1968) 591.

24. R. W. VEST and N. M. TALlan, J. Appl. Phys. 36 (1965) 543.

25. RICHARD A. SWALIN, "Thermodynamics of Solids", 2nd Edn (Wiley, New York, 1972).

Received 12 November 1986

and accepted 29 January 1987 